\title{
Southern California margin benthic foraminiferal assemblages across a modern environmental gradient record recent centennial-scale changes in oxygen minimum zone
}

Hannah M. Palmer ${ }^{1,2}$, Tessa M. Hill ${ }^{1,2}$, Peter D. Roopnarine ${ }^{3}$, Sarah E. Myhre ${ }^{4}$, Katherine R. Reyes $^{1,5}$, and Jonas T. Donnenfield ${ }^{1,6}$

${ }^{1}$ Bodega Marine Laboratory, University of California, Davis, California, USA

${ }^{2}$ Department of Earth and Planetary Sciences, University of California, Davis, California, USA

${ }^{3}$ Department of Invertebrate Zoology and Geology, California Academy of Sciences, San Francisco, California, USA

${ }^{4}$ School of Oceanography, University of Washington, Seattle, Washington, USA

${ }^{5}$ Department of Natural Sciences and Mathematics, Dominican University of California, San Rafael, California, USA

${ }^{6}$ Geology Department, Carleton College, Northfield, Minnesota, USA

This supplement contains three supplemental figures. All materials and methods for data collection are described in the main text of this article. 


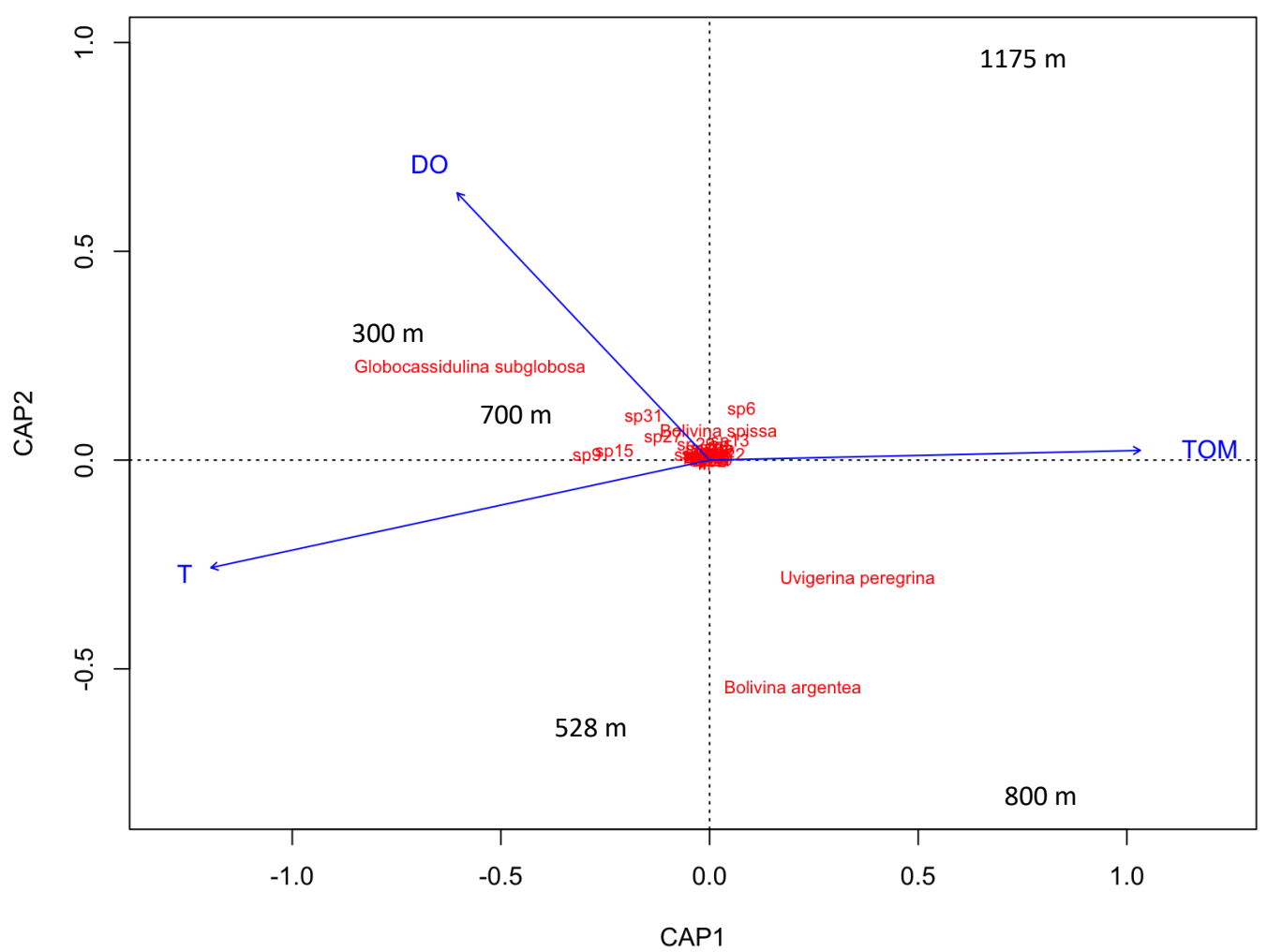

Figure S1. Distance Based Redundance Analysis of core-top benthic foraminiferal assemblages including both size fractions $(>63 \mu \mathrm{m})$. Species are listed in red - species discussed in manuscript are labeled. Sites are listed as water depth in meters. Blue arrows show ordination of environmental factors $\mathrm{T}=$ temperature, $\mathrm{DO}=$ dissolved oxygen, $\mathrm{TOM}=$ total organic matter). Eigenvalues for two axes are CAP1 (0.3658) and CAP2 (0.2505). 


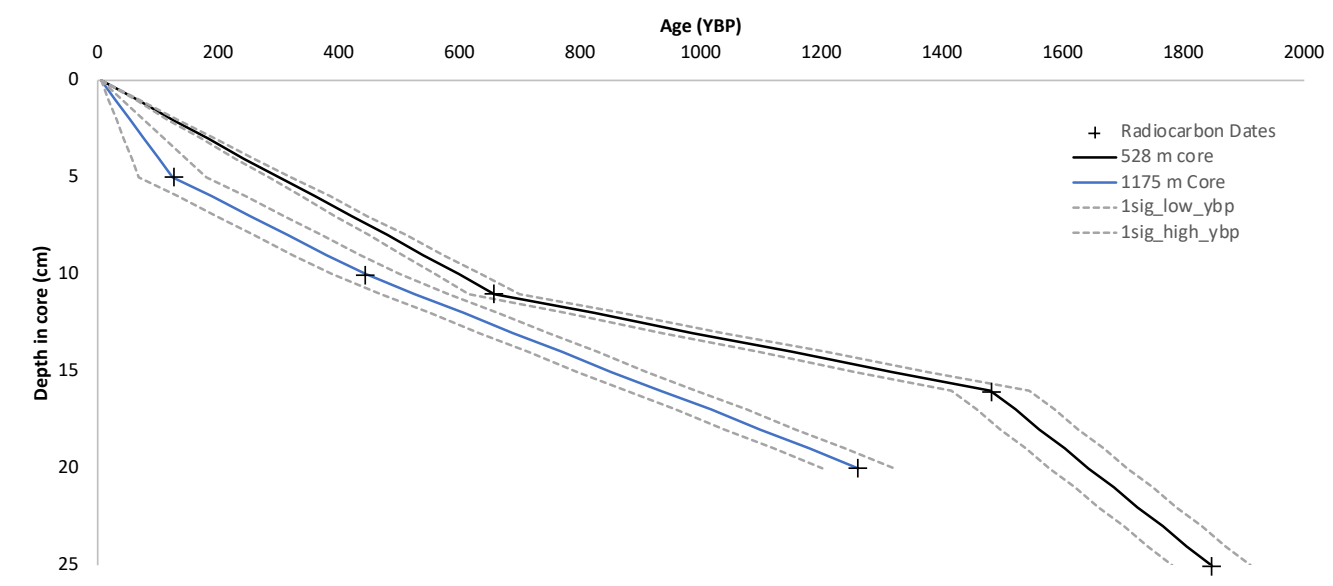

Figure S2. Age model for two cores. Age shown in years before present. Linear interpolation between radiocarbon dates (+). MV1217-2-3 (528 m water depth) is black line. MV1217-4-3 and MV1217-4-1 (1175 m) is blue line. Dashed lined represent $+/-1$ sigma years.

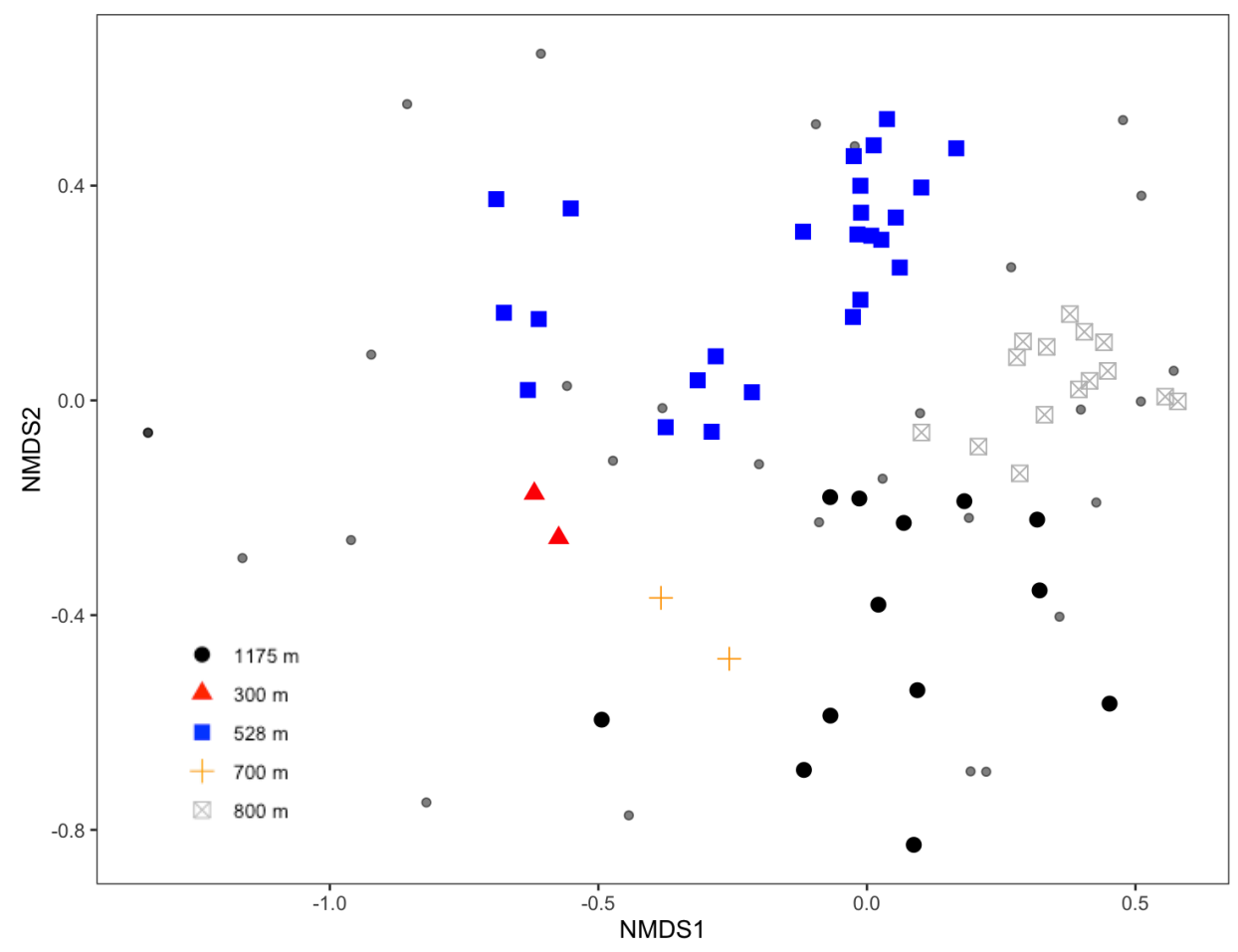

Figure S3. Non-metric multidimensional scaling plot of all benthic foraminiferal assemblages through time. Species are plotted as small gray dots. All other points represent assemblages from $1 \mathrm{~cm}$ intervals through time at each of the 5 cores. Legend shows which dots represent each water depth/site (Red triangle $=300 \mathrm{~m}$, blue square $=528 \mathrm{~m}$, orange crosshair $=700 \mathrm{~m}$, Grey box with $\mathrm{x}=800 \mathrm{~m}$, black circle $=1175 \mathrm{~m})$. 